\title{
Exposure to Atrazine Impairs Behaviour and Growth Performance in African Catfish, Clarias gariepinus (Burchell, 1822) Juveniles
}

\author{
Opute P. A. ${ }^{1, *}$ and Oboh I. P. ${ }^{2}$ \\ ${ }^{1,2}$ Department of Animal and Environmental Biology, University of Benin, Benin City, Edo State, Nigeria \\ Corresponding Author: *ashibudike.opute@ uniben.edu
}

https://doi.org/10.36263/nijest.2021.01.0263

\begin{abstract}
Clarias gariepinus juveniles of average weight, $17.57 \pm 1.95 \mathrm{~g}$ and an average length of $14.26 \pm 0.39$ $\mathrm{cm}$ were exposed to environmentally relevant concentrations of 0 (control), 2.5, 25, 250, and 500 $\mu g L^{-1}$ atrazine in a quality-controlled 28-day bioassay. Growth performance was assessed biweekly and fish samples were taken from different tanks to determine the relative growth rate, specific growth rate, feed conversion ratio, condition factor and behaviour. At the end of two weeks of exposure, the relative growth rate and the specific growth rate among exposed fish groups was found to reduce significantly $(p<0.05)$ compared to the control, an indication of poor growth performance. The average specific growth rates (SGR) of control fish is $3.86 \pm 0.02 \% / w$ at the end of the exposure duration while recording $-0.64 \pm 0.09$ in the $500 \mu \mathrm{g} \mathrm{L}^{-1}$ group. Feed conversion ratio increased significantly from control to the group with highest atrazine concentration. Condition factor $(K)$ of fish among treatment groups showed significant decrease in values with increasing concentration of atrazine in a dose-dependent pattern. Atrazine exposure resulted in behavioural anomalies including erratic swimming, clinging to the water surface, loss of equilibrium, lethargy, and discolouration. The behavioural responses were found to be concentration-dependent. The length-weight relationships for both control and atrazine exposed fish exhibited positive allometric growth and significant relationships as depicted by the value of $R^{2}$ (coefficient of determination) except in the fish group exposed to $500 \mu \mathrm{g} \mathrm{L}^{-1}$ atrazine which exhibited negative allometric growth. Findings from this study indicate interference with normal behaviour and growth performance of C. gariepinus juveniles with ecological implications in water bodies exposed to atrazine even at reduced concentrations.
\end{abstract}

Keywords: Clarias gariepinus, Atrazine, Behaviour, Growth, Condition factor

\subsection{Introduction}

Increased industrialization and agricultural production, as evident in Nigeria in recent years, has exacerbated environmental contamination by the introduction of anthropogenic compounds that are alien to living systems. The quest for food security has raised several concerns about how to feed the growing population of over 200 million people. Since the adoption of the Millennium Development Goals (MDGs) at the beginning of the twenty-first century, this has been a major topic in government circles (Ashe, 2019). The government has no choice but to encourage intensified agriculture beyond subsistence scale to adequately feed the country's teeming population. However, the use of pesticides and other agricultural chemicals to promote and enhance the quantity and quality of farm produce cannot be divorced from agricultural mechanization. Thus, pesticides have become an indispensable tool in large-scale agricultural development in Nigeria (Opute and Oboh, 2021). Despite the overwhelming benefits of pesticide use, warnings of significant health risks for humans and the environment have been reported. The potential risks to human health from both occupational and nonoccupational exposures, the death of farm animals, and the alteration of the local environment are all part of the health implications. Immunologic, teratogenic, carcinogenic, reproductive, and neurological issues are among the other side effects (Lushchaka, et al., 2018). Because of these health risks, most pesticide classes have been banned in developed and some developing countries. 
Fish are presumably the best-understood species in the aquatic environment and are also important to man as a source of animal protein, thus, they have become the most common choice as a test organism for toxicological studies. Also, because of their significance as a protein source, aquatic pollution influences humans indirectly through the ingestion of contaminated fish following the bioaccumulation of toxicants in their bodies. It is therefore important to evaluate the impact of pollution on fish for both environmental and socio-economic reasons. Clarias gariepinus is a commercially important freshwater fish whose production is rapidly growing around the world. Besides its economic value, $C$. gariepinus has been used in fundamental and ecotoxicological studies, and it is currently a model test species for environmental research (Opute et al., 2021).

Farmers in Nigeria use atrazine, a class III herbicide from the triazine family, as one of their most popular pesticides (Olatoye et al., 2021). It is a registered and approved herbicide for use in Nigeria by the National Agency for Food and Drug Administration and Control (NAFDAC). However, registration criteria often overlook the pesticides' subtle effects on non-target organisms, which can only be determined by comprehensive descriptive and mechanistic toxicological studies. Atrazine is one of the most commonly detected pesticides in streams, rivers, ponds, lakes, and ground waters, and it is rated moderately harmful to aquatic organisms. Despite considerable usefulness, there is a lack of knowledge on the fate and consequences of these chemicals after they have been applied to crop fields in areas where farmers are unaware of healthy practices and the threats they pose to their health (Opute and Oboh, 2021). Herbicides are still being found in water sources, indicating that regulatory strategies have flaws and are ineffective in ensuring end-user and environmental protection. In November 1989, Nigeria's then-president unveiled the country's national environmental policy (Kankara, 2013). The policy aimed to achieve sustainable development in Nigeria, including, among other things, ensuring a quality environment suitable for the health and well-being of all Nigerians, as well as conserving and using the environment and natural resources for the benefit of present and future generations. Environmental conservation programs, on the other hand, are only effective if the environment to be protected is well understood. The ecosystem should not be over-protected or underprotected in any way. Standards should, ideally, be focused on environmental baseline data collected across the country. Unfortunately, such data are scarce in Nigeria, and even when they are, they are vastly underutilized. Understanding the extent of potential adverse effects of atrazine on the behavioural and growth performance of $C$. gariepinus, a Pan-African and widespread food fish in most African countries, including Nigeria, would be an invaluable tool in assessing the environmental risks posed by this widely used pesticide to our immediate environment.

\subsection{Materials and Methods}

\subsection{Materials}

Atrazine with CAS No:1912-24-9; technical grade, and of $99.5 \%$ purity, purchased from AccuStandard Incorporated (New Haven, CT, USA) was used as test chemical. Three hundred (300) four-week-old $C$. gariepinus juveniles were procured from the aquaculture section of the department of fisheries and aquaculture, faculty of agriculture, university of Benin, and were kept in the animal house of the department of animal and environmental biology. Twenty (20) juvenile fish were assigned at random to each treatment and control tank. The juvenile fish weighed an average of 17.57 $\pm 1.95 \mathrm{~g}$ and measured $14.26 \pm 0.39 \mathrm{~cm}$ in length.

\subsection{Test chemical and water analysis}

Atrazine with CAS No:1912-24-9; technical grade, and of $99.5 \%$ purity was purchased from AccuStandard Incorporated (New Haven, CT, USA). In distilled water, a $25 \mathrm{mg} \mathrm{L}^{-1}$ atrazine stock solution was prepared (Milli-Q). The mixture was sonicated and warmed to $50^{\circ} \mathrm{C}$ for no more than 15 minutes to dissolve the atrazine (Zaya, 2011). Final exposure solutions were made by diluting the stock solution with nominal atrazine concentrations of 0 (Control), 2.5, 25, 250, and $500 \mu \mathrm{g} \mathrm{L}^{-1}$ in exposure water. Three replicates were prepared for each concentration. Throughout the 28-day exposure period, the concentrations of atrazine in all tanks were monitored weekly using enzymelinked immunosorbent assay (ELISA) kits (Abraxis, Warminster, PA) with $n=12$ (4 samples per replicate). The method detection limit (MDL) of the atrazine ELISA procedure was $0.05 \mu \mathrm{g} \mathrm{L}^{-1}$ of water. A confirmatory test was performed on atrazine stock solutions and selected tank water samples using gas chromatography (Jimenez et al., 1997). Water was obtained using methylene chloride, then 
dried with sodium sulfate and filtered through glass fibres. After that, the volume was reduced to 0.1 $\mathrm{mL}$ in methyl tertiary butyl ether (MtBE). Triphenylphosphate (Chem Service Inc., $500 \mathrm{ng} \mathrm{mL}^{-1}$ in $\mathrm{MtBE}$ ) was used as an instrumental internal standard. A GC/NPD (Gas Chromatographic/Nitrogen Phosphorus Detector) and PerkinElmers' TotalChromTM workstation chromatography data software was used to analyze the extracts. Samples for the GC/NPD analysis were obtained on three of the five days that water was collected. In each of the sample groups, triplicate water samples from each of the treatments $\left(0,2.5,25,250\right.$, and $\left.500 \mu \mathrm{g} \mathrm{L}^{-1}\right)$ were used. Each sample set included atrazine-spiked water, water-blank matrix (tap), and a blank procedural as quality control samples.

\subsection{Methods}

\subsection{Experimental design and treatment}

The research was conducted with the approval of the University of Benin's College Research Ethics Committee and under the institutional guidelines, laws, and regulations of the Federal Republic of Nigeria's National Code of Health Research Ethics; REC approval number: CMS/REC/2017/026. Three hundred (300) four-week-old C. gariepinus juveniles were procured from the aquaculture section of the department of fisheries and aquaculture, faculty of agriculture, university of Benin, and were kept in the animal house of the department of animal and environmental biology. Twenty (20) juvenile fish were assigned at random to each treatment and control tank. The juvenile fish weighed an average of $17.57 \pm 1.95 \mathrm{~g}$ and measured $14.26 \pm 0.39 \mathrm{~cm}$ in length. The fish were then allowed to acclimate for seven days before being fed commercial fish feed at 8 hourly intervals once daily (Aller aqua, Allervej 130, 6070 Christiansfeld, Denmark). For 28 days, the fish were exposed to four concentrations of atrazine $\left(2.5,25,250\right.$, and $\left.500 \mu \mathrm{g} \mathrm{L}^{-1}\right)$ and control $\left(0 \mu \mathrm{g} \mathrm{L}^{-1}\right)$ in a static renewal bioassay. The experimental tanks, which measured $670 \mathrm{~mm} \times 450 \mathrm{~mm} \times 355 \mathrm{~mm}$, were all correctly labelled as $\mathrm{AT}_{1}, \mathrm{AT}_{2}, \mathrm{AT}_{3}, \mathrm{AT}_{4}$, and $\mathrm{C}$, representing $2.5,25,250$, and $500 \mu \mathrm{g} \mathrm{L}^{-1}$ of atrazine concentrations and control $\left(0 \mu \mathrm{g} \mathrm{L}^{-1}\right)$, respectively. Three replicates of each concentration of test solutions were applied in a static-renewal exposure regime. Every 7 days, test solutions were renewed by $50 \%$ replacement to allow for maximum survival and to reduce stress on the fish caused by a sudden change in the water chemistry of the test media (Okomoda et al., 2016). A $12 \mathrm{~h}$ light:12 h dark photoperiod was used throughout the study period. Growth parameters were taken weekly throughout the four-week exposure duration.

\subsection{Measurement of growth performance}

Weight gain WG (g), specific growth rate (SGR, \% d-1) was calculated as the following formulae:

$W G=\left(W_{t}-W_{o}\right)$

$S G R=100 \times\left[\ln \left(W_{t}\right)-\ln \left(W_{o}\right)\right] /$ days

where $W_{o}$ and $W_{t}$ were initial body weight and body weights of fish at time $t(\mathrm{~g})$.

Feed conversion ratio (FCR): The feed conversation ratio was calculated using the formula below:

$F C R=$ Feed intake $/ W G$

Fulton's condition factor $(K)$ : Fulton's condition factor $(K)$ was calculated using the formula given below:

$K=\frac{W \times 100}{L^{3}}$

where, $W=$ weight of fish (g), $L=$ Length of fish (cm).

\subsection{Physicochemical analysis of treatment water}

The physicochemical parameters of the various treatment water samples, including $\mathrm{pH}$, Temperature, Conductivity, Total Dissolved Solids (TDS), and Dissolved Oxygen (DO), were measured throughout the study using standard methods (APHA, 2005). 


\subsection{Data analysis}

All the data were analyzed using the statistical package for social sciences (SPSS version 21). Data are presented as treatment means \pm standard deviation of the mean (SD). Data were analysed by oneway Analysis of Variance (ANOVA) to test significance among exposure chemical and concentrations with significance at $P<0.05$. Tukey's posthoc test was performed to compare the means of all treatments. Regression analysis was used to test for linear relationships between standard length (SL) and body weight (BW).

\subsection{Results and Discussion}

\subsection{Concentration of atrazine in exposure tanks}

Throughout the experiment, the concentration of atrazine in the exposure tanks remained relatively stable (Table 1). Mean atrazine concentrations in tank water were <MDL, $2.50 \pm 0.13,25.08 \pm 1.82$, $250.81 \pm 2.45$, and $500.14 \pm 4.57$ in the control, $\mathrm{AT}_{1}, \mathrm{AT}_{2}, \mathrm{AT}_{3}$, and $\mathrm{AT}_{4}$ groups, respectively.

Table 1: Atrazine concentrations in water $\left(\mathrm{gL}^{-1}\right)$ in Clarias gariepinus exposure tanks. The mean and standard deviation of atrazine ELISA determinations from each exposure tank $(n=12)$ are presented

\begin{tabular}{|c|c|c|c|c|c|c|}
\hline \multirow{2}{*}{$\begin{array}{c}\text { Water } \\
\text { treatment } \\
\left(\mu \mathrm{gL}^{-1}\right)\end{array}$} & \multicolumn{4}{|c|}{ Exposure Days } & \multirow[b]{2}{*}{ Day 28} & \multirow[b]{2}{*}{ Mean Conc. } \\
\hline & Day 0 & Day 7 & Day 14 & Day 21 & & \\
\hline Control & $<\mathrm{MDL}$ & $<\mathrm{MDL}$ & $<\mathrm{MDL}$ & $<\mathrm{MDL}$ & $<\mathrm{MDL}$ & $<\mathrm{MDL}$ \\
\hline $\mathrm{AT}_{1}$ & $2.60 \pm 0.13$ & $2.49 \pm 0.12$ & $2.47 \pm 0.08$ & $2.46 \pm 0.11$ & $2.50 \pm 0.13$ & $2.50 \pm 0.13$ \\
\hline $\mathrm{AT}_{2}$ & $25.64 \pm 1.61$ & $24.91 \pm 1.28$ & $24.53 \pm 1.50$ & $25.02 \pm 2.32$ & $25.30 \pm 2.41$ & $25.08 \pm 1.82$ \\
\hline $\mathrm{AT}_{3}$ & $251.70 \pm 1.90$ & $250.02 \pm 2.02$ & $250.15 \pm 2.41$ & $251.03 \pm 3.11$ & $251.15 \pm 2.81$ & $250.81 \pm 2.45$ \\
\hline $\mathrm{AT}_{4}$ & $499.81 \pm 3.12$ & $500.53 \pm 4.33$ & $498.55 \pm 4.80$ & $501.22 \pm 4.11$ & $500.59 \pm 6.48$ & $500.14 \pm 4.57$ \\
\hline
\end{tabular}

*MDL: The method detection limit.

\subsection{Behavioural performance of juveniles}

Sub-lethal atrazine exposure of Clarias gariepinus juveniles resulted in different responses and tolerance to different atrazine treatment concentrations (Table 2). Anomalies observed included erratic swimming, clinging to the water surface, loss of equilibrium or balance, lethargy, and discolouration. The behavioural responses were found to be concentration-dependent, with increasing concentration resulting in the intensity of the behavioural responses. The bioassay results revealed that exposed juveniles showed signs of stress, such as slow and uncoordinated movement. Abnormalities increased as atrazine concentrations increased. Our findings are similar to the report of Marzouk et al. (2012) on female Clarias gariepinus. They observed that the effects of both acute and chronic exposures revealed clinical abnormalities which were manifested by loss of appetite, sluggish or restlessness, rapid opercular movements and abnormal skin pigmentation in the form of faded skin. Xing et al. (2012b) reported an abnormal response on behaviour and feeding. The authors reported that fish exposed to atrazine at $428 \mu \mathrm{gL}^{-1}$ showed abnormal behaviour, including decreased intake of food, slower swimming speed, and unresponsiveness to outside stimuli. In the present study, increase in the respiratory movements was observed during entire period of the bioassay, while fishes became inactive and almost non-motile with clinical signs of fading of body colour, erosion of scales, lesions, and hemorrhagic patches all over the body especially on the ventral side. Similar changes were observed by Elias et al. (2018). They reported several distinct unusual swimming behaviour and increased deformities in fish exposed to sub-lethal concentration of thiobencarb. These behaviours include lack of balance, agitated or jerky swimming, air gulping, sudden quick movement, and excessive secretion of mucus. Moreover, the colour of fish skin was changed from normal darkly pigmentation in the dorsal and lateral parts to very light pigmentation in the dorsal and lateral part, as well as peeling of the skin was observed. Hyperactivity in C. gariepinus exposed to atrazine was reported by Mekkawy et al. (2013), which was characterized by rapid and irregular swimming or darting, partial loss of equilibrium, rapid pectoral fins and opercular movements, reduction in feeding activity. A possible explanation for this, as well as other unusual behaviours, is likely a nervous system failure caused by pesticide poisoning, which affects physiological and biochemical activities. 
Table 2: Behavioural observations of Clarias gariepinus juveniles after 28day exposure to varying concentrations of atrazine

\begin{tabular}{|l|c|c|c|c|c|}
\hline Behaviour & Control & $\mathrm{AT}_{1}$ & $\mathrm{AT}_{2}$ & $\mathrm{AT}_{3}$ & $\mathrm{AT}_{4}$ \\
\hline Erratic swimming & - & - & + & + & + \\
\hline Loss of Balance & - & + & + & ++ & +++ \\
\hline Discolouration & - & + & + & +++ & +++ \\
\hline Lethargy & - & + & + & ++ & +++ \\
\hline Hanging on water Surface & - & + & ++ & ++ & +++ \\
\hline
\end{tabular}

$(+)$ indicates increasing response; (-) indicates no response

\subsection{Growth performance of Juveniles}

Atrazine was found to significantly affect the growth of the juveniles (Table 3). The total length and body weight showed significant decrease with increasing concentration of atrazine during the four weeks of exposure. At the end of two weeks of exposure, the standard length ranged from 15.02 to $16.01 \mathrm{~cm}$ in the control group and 13.10 to $14.87 \mathrm{~cm}$ in the $500 \mu \mathrm{gL}^{-1}$ treatment group. Similar trend was observed in body weight which ranged from 32.75-32.99g in the control group and 22.62 to $22.67 \mathrm{~g}$ in the $500 \mu \mathrm{gL}^{-1}$ treatment group. The decrease in growth observed followed the same dose dependent pattern even in the last two weeks of exposure (Table 4). The final average specific growth rates (SGR) of control fish ranged from 4.45 to $4.50 \% / w$ in the first two weeks. Similarly, during the first 2 weeks of exposure, fish from all the treatment groups displayed significantly $(\mathrm{p}<0.05)$ lower SGR than in control groups (Table 4). Again, in the 2nd week of exposure, the SGR of all the atrazine-exposed fish further decreased with concentration toward the termination of the test while the values increased in the control. Results of the condition factor $(K)$ of both control and treated groups are presented in Table 3. The results showed significant decrease in the values of $K$ with increasing concentration of atrazine in a dose dependent pattern. The condition factor of the treatment groups significantly declined from the control $(0.97 \pm 0.36)$ except for the $250 \mu \mathrm{gL}^{-1}$ treatment group $(0.95 \pm 0.39)$ in the first two weeks. After the first two weeks of exposure, the mean feed conversion ratio (FCR) in the control group was $0.07 \pm 0.02$ while $0.21 \pm 0.09$ was recorded for the highest treatment concentration, indicating a significant $(\mathrm{p}<0.05)$ increase in FCR with increasing concentration of atrazine. However, the next two weeks of continuous exposure did not reveal any pattern in the FCR (Table 4).

Table 3: Summary of growth performance of $C$. gariepinus juveniles exposed to varying concentrations of atrazine (Week 2)

\begin{tabular}{|c|c|c|c|c|c|c|c|}
\hline Parameters & Control & AT1 & AT2 & AT3 & AT4 & P-value & Significance \\
\hline ISL $(\mathrm{cm})$ & $14.26 \pm 0.39$ & $14.26 \pm 0.39$ & $14.26 \pm 0.39$ & $14.26 \pm 0.39$ & $14.26 \pm 0.39$ & 1.000 & $p>0.05$ \\
\hline FSL $(\mathrm{cm})$ & $15.02 \pm 0.27$ & $14.78 \pm 0.29$ & $14.64 \pm 0.90$ & $14.45 \pm 0.22$ & $14.33 \pm 0.56$ & 0.000 & $p<0.05$ \\
\hline IW $(\mathrm{g})$ & $17.57 \pm 1.95$ & $17.57 \pm 1.95$ & $17.57 \pm 1.95$ & $17.57 \pm 1.95$ & $17.57 \pm 1.95$ & 1.000 & $p>0.05$ \\
\hline FW $(\mathrm{g})$ & $32.82 \pm 1.78$ & $28.78 \pm 5.95$ & $27.64 \pm 3.09$ & $25.89 \pm 1.20$ & $22.64 \pm 3.31$ & 0.000 & $p<0.05$ \\
\hline SGR $(\% / w)$ & $4.46 \pm 0.00$ & $3.52 \pm 0.01$ & $3.24 \pm 0.00$ & $2.77 \pm 0.00$ & $1.81 \pm 0.00$ & 0.000 & $p<0.05$ \\
\hline RGR $(\% / w)$ & $108.96 \pm 34.46$ & $80.06 \pm 25.32$ & $71.96 \pm 22.76$ & $59.44 \pm 18.79$ & $36.24 \pm 11.46$ & 0.000 & $p<0.05$ \\
\hline FCR & $0.07 \pm 0.02$ & $0.09 \pm 0.04$ & $0.10 \pm 0.04$ & $0.13 \pm 0.05$ & $0.21 \pm 0.09$ & 0.000 & $p<0.05$ \\
\hline K & $0.97 \pm 0.36$ & $0.89 \pm 0.36$ & $0.88 \pm 0.35$ & $0.95 \pm 0.39$ & $0.89 \pm 0.36$ & 0.000 & $p<0.05$ \\
\hline
\end{tabular}

Data are presented as mean \pm SD. Different letters indicate significant differences between treatments. IL-Initial length; FL-

Final length; IW-Initial weight; RGR-Relative growth rate; FCR-Feed conversion ratio; K-Condition factor. P-value of 1.000 indicates no significance

Table 4: Summary of growth performance of $C$. gariepinus juveniles exposed to varying concentrations of atrazine (Week 4)

\begin{tabular}{|c|c|c|c|c|c|c|c|}
\hline Parameters & Control & AT1 & AT2 & AT3 & AT4 & P-value & Significance \\
\hline ISL $(\mathrm{cm})$ & $15.02 \pm 0.27$ & $14.78 \pm 0.29$ & $14.64 \pm 0.90$ & $14.45 \pm 0.22$ & $14.33 \pm 0.56$ & 0.000 & $p<0.05$ \\
\hline FSL $(\mathrm{cm})$ & $18.14 \pm 0.75$ & $16.62 \pm 0.62$ & $15.68 \pm 0.43$ & $14.96 \pm 0.16$ & $14.81 \pm 0.61$ & 0.000 & $p<0.05$ \\
\hline IW $(\mathrm{g})$ & $32.82 \pm 1.78$ & $28.78 \pm 5.95$ & $27.64 \pm 3.09$ & $25.89 \pm 1.20$ & $22.64 \pm 3.31$ & 0.000 & $p<0.05$ \\
\hline FW $(\mathrm{g})$ & $56.31 \pm 6.17$ & $42.37 \pm 9.07$ & $35.35 \pm 4.07$ & $23.98 \pm 2.58$ & $20.10 \pm 2.63$ & 0.000 & $p<0.05$ \\
\hline SGR $(\% / \mathrm{w})$ & $3.86 \pm 0.02$ & $2.76 \pm 0.03$ & $1.76 \pm 0.02$ & $-0.55 \pm 0.06$ & $-0.64 \pm 0.09$ & 0.000 & $p<0.05$ \\
\hline RGR $(\% / \mathrm{w})$ & $167.75 \pm 0.97$ & $97.09 \pm 1.07$ & $55.07 \pm 0.60$ & $-13.64 \pm 1.35$ & $-18.21 \pm 1.21$ & 0.000 & $p<0.05$ \\
\hline FCR & $0.04 \pm 0.02$ & $0.07 \pm 0.02$ & $0.14 \pm 0.06$ & $-0.55 \pm 0.22$ & $-0.41 \pm 0.17$ & 0.000 & $p<0.05$ \\
\hline K & $0.94 \pm 0.38$ & $0.92 \pm 0.38$ & $0.91 \pm 0.38$ & $0.71 \pm 0.29$ & $0.70 \pm 0.29$ & 0.000 & $p<0.05$ \\
\hline
\end{tabular}

Data are presented as mean \pm SD. Different letters indicate significant differences between treatments. IL-Initial length; FLFinal length; IW-Initial weight; RGR-Relative growth rate; FCR-Feed conversion ratio; K-Condition factor 
Several factors such as the difference in feed intake or the difference in the food metabolism (Lal et al., 2013) could explain the retardation observed in growth of the exposed fish. Another important factor that may be responsible for the reduction in growth rate could be the transformation into energy of a portion of nutrients from digestion of food consumed to cope with chemical stress as a result of exposure to atrazine. This may explain the observed increase in feed conversion ratio of exposed fish with increasing treatment concentration.

Toxicants inhibit fish growth, with the severity of this effect being dose dependent (Opute and Oboh, 2021). Toxicants can influence growth directly or indirectly by its effects on feeding because these processes are intertwined. Reduced physical activity can have an indirect effect on feeding and, as a consequence, growth. Fish, for example, appear to increase their metabolic activities toward toxicant excretion, thereby freeing up more energy for homeostatic maintenance rather than storing it for growth (Elias et al., 2018). Also, Lal et al. (2013) reported a significant decline in plasma levels of growth hormone $(\mathrm{GH})$ and insulin-like growth factor (IGF-I) in malathion exposed Asian stinging catfish, Heteropneutes fossilis. They showed that this decline was related to reduction in fish growth, and also due to low food intake and influence of the pesticide on metabolization of feed into somatic growth. Similar findings of weight reduction have been reported in Australian catfish, Tandanus tandanus exposed to 2-10 $\mathrm{mgL}^{-1}$ of chlorpyrifos (Huynh and Nugegoda, 2012). Heavy metal pollution has also been implicated with reduced growth rate caused by high metabolic cost (Xie et al., 2014). They reported that reduced feed conversion rate in marine organisms at sub-lethal levels of heavy metals might be due to the tissue burden of heavy metals, which in turn could cause increase in metabolic cost. The retarded growth observed in the exposed juveniles of $C$. gariepinus could be attributed to the inhibition of acetylcholinesterase as reported by Lecomte et al. (2018). Acetylcholinesterase is an enzyme normally responsible for inactivation of the neurotransmitter, acetylcholine, at synaptic and neuro-effector endings of cholinergic motor and secreto-motor neurons in the enteric nervous system. Inhibition of enzyme activity allows accumulation of acetylcholine leading to increased motor activity in the gastrointestinal tract caused by stimulation of smooth muscle M3 muscarinic receptors. The accumulated acetylcholine also acts at M1 and M3 muscarinic receptors to increase salivary, gastric, pancreatic, and intestinal secretions. Extensive inhibition of acetylcholinesterase leads to the secretion of large volumes of fluid and electrolytes into the lumen of the intestine, which results in profuse, watery diarrhoea (Haschek et al., 2010). In this study, inhibition of acetylcholinesterase in exposed fish may have resulted to serious decline in the efficient use of the dietary proteins in fish feeds resulting in growth retardation.

The length-weight relationship (LWR) of the exposed juveniles was also estimated. The length-weight relationships for both control and atrazine exposed fish exhibited positive allometric growth and significant relationships as depicted by the value of $\mathrm{R}^{2}$ (Coefficient of determination) with $\mathrm{b}$ values of 4.31, 5.14, 6.60 and 4.73 for control, $\mathrm{AT}_{1}, \mathrm{AT}_{2}$ and $\mathrm{AT}_{3}$, respectively (Table 5). However, fish in tank $\mathrm{AT}_{4}$ exhibited negative allometric growth with ' $\mathrm{b}$ ' value of 0.95 . This observation indicates that although atrazine had significant effect on the growth rate and condition factor, it however did not affect the pattern of growth. Length-weight relationships are commonly used in fisheries biology to convert length measurements into weight and to ascertain the growth characteristics related to those variables. On the other hand, length-weight relationships are also used for estimating fish condition factor and these values are used for comparing the condition (fatness or well-being) of fish (Jisr et al., 2018). The condition factor could reflect the physiological state of a fish, which is influenced by both intrinsic (gonadal development, organic reserves, presence or absence of food in the gut) and extrinsic (food availability, environmental variability) factors (Flura et al., 2015). The decrease in fish weight gain and specific growth rate observed with increasing atrazine concentrations in this study is attributed to energy being directed toward homeostatic processes and tissue damage repair to offset the toxicant's impact, rather than storage and growth. 
Table 5: Final length-weight relationship of C. gariepinus juveniles exposed to varying concentrations of atrazine for 28days

\begin{tabular}{|c|c|c|c|c|c|c|c|}
\hline TANK & FAW $(\mathrm{g})$ & FSGR (\%/) & Logarithm Equation Log & 'R' & 'R ${ }^{2}$ & 'FAK' & 'b' \\
\hline Cont. & $44.57 \pm 5.25$ & $4.16 \pm 0.13$ & $\log$ W=Log $-3.651+4.308$ Log L & 0.9359 & 0.876 & 0.96 & 4.308 \\
\hline $\mathrm{AT}_{1}$ & $35.58 \pm 3.04$ & $3.14 \pm 0.17$ & $\log \mathrm{W}=\log -4.627+5.138 \log \mathrm{L}$ & 0.9327 & 0.870 & 0.91 & 5.138 \\
\hline $\mathrm{AT}_{2}$ & $31.49 \pm 1.72$ & $2.50 \pm 0.33$ & $\log \mathrm{W}=\log -6.324+6.602 \log \mathrm{L}$ & 0.9121 & 0.832 & 0.89 & 6.602 \\
\hline $\mathrm{AT}_{3}$ & $24.94 \pm 0.43$ & $1.11 \pm 0.74$ & $\log \mathrm{W}=\log -4.153+4.729 \log \mathrm{L}$ & 0.5701 & 0.325 & 0.83 & 4.729 \\
\hline $\mathrm{AT}_{4}$ & $21.37 \pm 0.57$ & $0.59 \pm 0.55$ & $\log \mathrm{W}=\log 0.199+0.948 \log \mathrm{L}$ & 0.1517 & 0.023 & 0.79 & 0.948 \\
\hline
\end{tabular}

FAW-Final average weight; FSGR-Final average specific growth rate; R-Correlation coefficient; $\mathrm{R}^{2}$ - Coefficient of determination; FAK-Final average condition factor; b-Slope

\subsection{Conclusions}

This study found that exposing Clarias gariepinus juveniles to very low concentrations of atrazine interfered with their normal behaviour and growth performance. More energy was directed toward the detoxification process in exposed fish juveniles, resulting in a higher feed conversion ratio and less energy for growth. This suggests that atrazine exposure slowed the growth of C. gariepinus, particularly during the juvenile stage. Furthermore, given the detected effects of atrazine in $C$. gariepinus even at reduced concentrations, it is safe to conclude that the unregulated use of atrazine as a herbicide in Nigerian may result in increased atrazine accumulation in fish via aerosol or runoff, leaving a residue in aquatic animals. Pesticide usage regulation will promote food safety and public health across the country by proper legislation, routine pesticide monitoring of fish and fish products, and corrective steps to decrease residue occurrence with suitable sanctions for noncompliance.

\section{References}

APHA (2005). Standard methods for the examination of water and wastewater, 21st edition. American Public Health Association, Washington, DC.

Ashe, M. O. (2019). International Agencies and the Quest for Food Security in Nigeria, 1970-2015. Journal of Conflict and Social Transformation. Special issue, pp. 251-274

Elias, N.S., Abouelghar, G.E., Sobhy, H.M., El Miniawy, H.M. and Elsaiedy E.G. (2018). Sublethal effects of the herbicide thiobencarb on fecundity, histopathological and biochemical changes in the African catfish (Clarias gariepinus). Iranian Journal of Fisheries Sciences, 19(3), pp. 1589-1614.

Flura, Zaher, M., B.M. Rahman, S., Rahman, A., Alam, M. A. and Pramanik, M. H. (2015). Lengthweight relationship and GSI of hilsa, Tenualosa ilisha (hamilton, 1822) fishes in Meghna river, Bangladesh. International Journal of Natural and Social Sciences, 2, pp. 82-88.

Haschek, W. M., Rousseaux, C. G. and Wallig, M.A. (2010). Gastrointestinal tract. In Fundamentals of Toxicologic Pathology (Haschek, W.M., Rousseaux, and C.G., Wallig, M.A., eds.), 2nd ed., pp. 163-96. Elsevier, London, UK.

Huynh, H.P.V. and Nugegoda, D. (2012). Effects of Chlorpyrifos exposure on growth and food utilization in Australian catfish, Tandanus tandanus. Bulletin of Environmental Contamination and Toxicology, 88, pp. 25-29.

Jimenez, J. J., Bernal, J. L., del Nozal, M. J. and Rivera, J. M. (1997). Determination of pesticide residues in water from small loughs by solid-phase extraction and combined use of gas chromatography with electron capture and nitrogen-phosphorous detection and high-performance liquid chromatography with diode array detection. The Journal of Chromatography A, 778, pp. 28930.

Jisr, N., Younes, G., Sukhn, C. and El-Dakdouki, M. H. (2018). Length-weight relationships and relative condition factor of fish inhabiting the marine area of the Eastern Mediterranean city, TripoliLebanon. Egyptian Journal of Aquatic Research, 44, pp. 299-305.

Kankara, A. I. (2013). Examining Environmental Policies and Laws in Nigeria. International Journal of Environmental Engineering and Management, 4(3), pp. 165-170. 
Lal, B., Sarang, M. K. and Kumar, P. (2013). Malathion exposure induces the endocrine disruption and growth retardation in the catfish, Clarias batrachus (Linn). General and Comparative Endocrinology, 181, pp. 139-145.

Lecomte, M., Bertolus, C., Ramanantsoa, N., Saurini, F., Callebert, J., Namaud-Beaufort, C. S., et al. (2018). Acetylcholine Modulates the Hormones of the Growth Hormone/Insulin-like Growth Factor-1 Axis During Development in Mice. Endocrinology, 159(4), pp. 1844-1859.

Lushchaka, V. I., Matviishyna, T. M., Husaka, V. V., Storeyb, J. M. and Storey, K. B. (2018). Pesticide Toxicity: A Mechanistic Approach. EXCLI Journal, 17, pp. 1101-1136.

Marzouk, M. S., Kadry, S. M., Amer, A.M., Hanna, M.I., Azmy, I.H. and Hamed, H. S. (2012). Effect of Atrazine Exposure on Behavioral, Haematological and Biochemical Aspects of Female African Catfish (Clarias gariepinus). Journal of Scientific Research in Science, 29, pp. 110-130.

Mekkawy, I. A. A., Mahmoud, U. M. and Mohammed, R. H. (2013). Protective effects of tomato paste and Vitamin E on atrazine-induced hematological and biochemical characteristics of Clarias gariepinus (Bürchell, 1822). Global Advanced Research Journal of Environmental Science and Toxicology, 2(1), pp. 11- 21.

Okomoda, V. T., Tiamiyu, L. O. and Iortim, M. (2016): The effect of water renewal on growth of Clarias gariepinus fingerlings. Croatian Journal of Fisheries, 74, pp. 25-29.

Olatoye, I. O., Okocha, R. C., Oridupa, O. A., Nwishienyi, C. N., Tiamiyu, A. M. and Adedeji, O. B. (2021). Atrazine in fish feed and african catfish (Clarias gariepinus) from aquaculture farms in Southwestern Nigeria. Heliyon, 7 , e06076.

Opute, P. A. and Oboh, I. P. (2021). Effects of Sub-Lethal Atrazine Concentrations on Embryogenesis, Larval Survival and Growth of African catfish, Clarias gariepinus (Burchell, 1822). Aquaculture Studies, 21, pp. 143-152

Opute, P. A., Udoko, A. O., Oboh, I. P. and Mbajiorgu, F. E. (2021) Changes induced by atrazine in Clarias gariepinus provide insight into alterations in ovarian histoarchitecture and direct effects on oogenesis, Journal of Environmental Science and Health, Part B, 56 (1), pp. 30-40

Xie, Y., Hu, L., Du1, Z., Sun, X., Amombo, E., Fan, J., Fu, J. (2014). Effects of Cadmium Exposure on Growth and Metabolic Profile of Bermudagrass [Cynodon dactylon (L.) Pers.]. PLoS ONE, 9(12), e115279

Xing, H., Li, S., Wang, Z., Gao, X., Xu, S.,Wang, X. (2012b). Oxidative $\quad$ stress $\quad$ response $\quad$ and histopathological changes due to atrazine and chlorpyrifos exposure in common carp. Pestic Biochem Physiol, 103, pp. 74-80.

Zaya, R. M. (2011). Molecular, cellular and systemic effects of atrazine on the xenopus laevis tadpole. dissertations, Western Michigan University. 488. https://scholarworks.wmich.edu/dissertations/488 